\title{
Michał Wendland*
}

\section{ANTI-PSYCHOLOGISM IN WITTGENSTEIN'S PHILOSOPHY IN REFERENCE TO THEORIES OF COMMUNICATION}

\begin{abstract}
This article aims to investigate the validity of criticism of what is known as psychologist-transmission communication theory. It is accepted that theories which support the idea that communication is a process of conveying (transmitting) psychological content of the mental states between participants (e.g. theories of Jakobson, Hovland, Newcomb et al.) are examples of the approach. There are doubts about such views, which arise from the assumptions of anti-psychologism and anti-mentalism (such as Frege, Husserl), as well as the rejection of traditional notions of subjectivity in philosophy after the linguistic turn. In order to justify the criticism the position of the "late" Wittgenstein is invoked, according to which communication activities (as well as thinking, understanding etc.) need not be considered as correlated to mental acts.
\end{abstract}

Key words: Wittgenstein, communication act, communication theory, psychologism, anti-psychologism

\section{INTRODUCTION}

Many contemporarily formulated and accepted communication theories include elements of psychologism (and/or mentalism). It may be observed that such components are integral to certain communication theories, being deliberately implemented by researchers, or that psychologist (mentalist) components underlie some theories, or are implied by them, although they are not voiced explicitly or directly. It would be hard not to notice that elements of psychologism are very common in the transmission models of communication. By transmission models of communication (also known as "telegraphic" or "linear") I refer to all such models in which it is assumed that the communication process involves the transfer of content (often identified as information) between the participants in the process (the sender and the recipient). The creators of the classic transmission communication models include Claude Shannon, Harold Laswell, Wilbur Shramm and Theodore Newcomb. The purpose of this paper is to attempt to reconstruct the psychologist-transmission approach to communication and to consider the possibility and advisability of its criticism. The anti-psychologist position of Ludwig Wittgenstein in relation to language will serve as an example of philosophical criticism of the presence of psychologism in communication theories (and even challenge said criticism).

* Adam Mickiewicz University, wendland@amu.edu.pl 


\section{DISPUTE BETWEEN ANTI-PSYCHOLOGISM AND PSYCHOLOGISM}

The term psychologism will be used to mean a philosophical position whose most comprehensive, most common and yet orthodox form was formulated in the second half of the nineteenth century by Franz Brentano and John Stuart Mill and their followers (such as Wilhelm Wundt, Hans Cornelius, Theodor Lipps ${ }^{1}$, and Friedrich Beneke) ${ }^{2}$.

I refer to the classic (though not uncontroversial) differentiation between "psychologism" and "mentalism". Psychologism is usually understood as a position according to which a given theoretical problem is reducible to psychological concepts or may be explained (solved) using psychological terms. While the term 'mentalism' usually stands for a view referring not as much to solving methodological problems, as to the status of certain objects, assumed within the framework of a given theory - namely the idea that such objects are of mental (psychological) character or are dependent on mental (psychological) acts. Sometimes the terms "strong version" and "weak version" of psychologism may be employed:

Weak logical psychologism holds the view that psychological inquiry into actual human thought processes constitutes necessary but not sufficient conditions for inquiry into the foundation of logic. Strong logical psychologism considers logic to be a branch of psychology, the laws of logic to be descriptive laws of actual human thought processes, and understands these laws as making assertions about mental events (Mohanty 1982: 20).

These positions are complementary.

As we know, the psychologist position was met with strong opposition from e.g. phenomenology (Edmund Husserl, Martin Heidegger, Roman Ingarden) and formal logic (Gottlob Frege, Bertrand Russell). There is no need to quote at this point the well-known story of this dispute. It is enough to highlight, for the purpose of the following argument, that in the history of the debate between psychologism and anti-psychologism it is possible to distinguish two basic points of disagreement between them. Husserl wrote:

Here we encounter the disputed question as to the relation between psychology and logic, since one dominant tendency of our time has a ready answer to the questions raised: The essential theoretical foundations of logic lie in psychology, in whose field those propositions belong - as far as their theoretical content is concerned - which give logic its characteristic pattern. Logic is related to psychology just as any branch of chemical technology is related to chemistry, as land-surveying is to geometry etc. (Husserl 2001: 30).

The first, more specific, controversial issue concerns the possibility of psychologically establishing the foundations of mathematics and logic; these issues will not, however, be dealt with in detail here. The more important of these considerations is the second, more general

1 Though in 1902 Lipps acknowledged Husserl's anti-psychologist arguments are valid.

2 The term ,psychologism” was introduced in 1866 by Johann E. Erdmann and since the early twentieth century has pervaded mainly German philosophy. As Windelband wrote, "throughout the nineteenth century the terrible [my emphasis - MW] domination of psychologism became extremely common and widely present, especially at German universities". (Windelband 1993: 539). 
issue in the dispute between psychologism and anti-psychologism, methodological in nature, and concerning not only the formal sciences, but in general all the sciences and the theoretical status of their subjects. In this case psychologism implies that empirical psychology is the basis for other fields of knowledge (including the various branches of philosophy), and that psychological concepts can and should be used to solve specific problems within the scientific and philosophical disciplines. I believe one can also speak of psychologist (and mentalist) theories of communication, the criticism of which is the main point of this article.

With regard to communication theory both psychologist and mentalist positions can be formulated, as well as opposing ones. According to the above distinction, one can say that psychologism in a given theory of communication assumes that the areas of interest to the science of communication may be explained by means of psychological terms, and reduced to the realm of psychological phenomena. Also accordingly, mentalism in communication theory is expressed in the belief that the communicated content is located in the psyche of the participants in communication and transmitted between them (as a psychological entity). As it can be imagined, the representatives of anti-psychologism and anti-mentalism, within the framework of the communication theory, would receive the above claims with varying degrees of scepticism, or would simply reject them.

\section{PSYCHOLOGIST-TRANSMISSION MODELS OF COMMUNICATION}

It is not difficult to realize that the themes of psychologism and mentalism are present in many contemporary communication theories, especially those referred to as transmissive. Several classical communication theories may be considered as psychologist-transmission, including those of Roman Jakobson (taking into account his description of the expressive communication function), Carl Hovland ("I should like to define communication as the process by which an individual (the communicator) transmits stimuli (usually verbal symbols) to modify the behaviour of other individuals", (Hovland 2007: 320), Theodore Newcomb ("Every communication act is viewed as a transmission of information, consisting of a discriminative stimuli, from a source to a recipient", Newcomb 1966: 66). Among the numerous approaches to communication of this kind, Bernard Berelson's definition is also worth mentioning here ("Communication: the transmission of information, ideas, emotions, skills, etc., by the use of symbols - words, pictures, figures, graphs, etc. It is the act or process of transmission that is usually called communication", Berelson 1964: 254), as well that of John Hoben ("Communication is the verbal interchange of thought or idea", Hoben 1954: 77).

Naturally, I mention here only a few examples of the most famous ones. Surely there are many more such psychologist (or mentalist) interpretations of communication. Recalling the assertions contained therein, one may be tempted to try to reconstruct the standard psychologist-transmission idea of communication. The result of such a reconstruction would be more or less as follows: it is assumed that communication is a transfer (transmission) of psychological (intellectual or emotional) content by subject A (the sender) to subject (or subjects) B (the recipient). The term "psychological content" usually means what you think or what you feel (mental act). The very transfer of psychological content (its transmission) 
is made through a given (external, perceived sensuously) medium. The medium assumes various forms, such as words (in the case of verbal communication), gestures (in the case of non-verbal communication), graphic signs, etc.

Subsequently, in psychologist-transmission models it is assumed that communication consists of encoding and decoding. What is encoded (by the sender) and decoded (by the recipient) is the "psychological content". Encoding involves "coating" of the communicated psychological content with a form of communicative means (e.g. a word as an articulated sound). The encoded thought (often regarded as information) is then transferred (transmitted) between participants of the communication process via an empirical medium: the recipient receives the encoded psychological content, "coated" with a sign, through the senses (sight, hearing, etc.). Afterwards, he decodes the given sign, i.e. "extracts" the underlying psychological content from it, making it the content of his own psyche, cognitively available and understandable to him at that point. The condition for a successful completion of the communication process is the participants' common knowledge of a shared code. This idea of communication is found in many earlier studies, from the $1950 \mathrm{~s}$ and $60 \mathrm{~s}^{3}$. However, similar approaches to communication may also be found half a century later: for example Kathleen Galvin and Charles Wilkinson wrote that "communication is the symbolic process of sharing meanings (...). Although verbal and nonverbal symbols permit us to transmit thoughts and feelings, the symbols must be mutually understood for the meanings to be truly shared" (Galvin 2006: 5-7).

Of course, this reconstruction is a simplified and generalized compilation of many positions, but I assume that it contains at least the most important features of the psychologist and transmission communication models. It is also worth mentioning - which will be of significance for further arguments - that this way of thinking about communication roughly corresponds to ordinary, common-sense ideas of what communication is. Scholars often consider the above psychologist-transmission communication model as a kind of axiom, a foundation for any further consideration of communication. The universality of its occurrence and acceptance, however, should not be the only guarantee of the theoretical value and quality of this model. If many of today's communication theories include elements of psychologism, and psychologism was attacked and questioned repeatedly in the past by prominent philosophers of the nineteenth and twentieth centuries, then its presence in the reflection on communication should be treated at least with some degree of suspicion and mistrust. An uncritical and thus dogmatic acceptance of the elements of psychologism in communication science is therefore risky from the perspective of methodological criteria. I will refer to at least one philosophical assumption from among those that allow for a challenge to the validity of the psychologist-transmission model, and that is the position of the "late" Wittgenstein.

Before doing so, however, let us tackle the question about the philosophical source of such an idea of communication, because if psychologist models of communication are to be

3 For example Alfred Afer wrote: “we use the word 'communication' sometimes to refer to what is so transferred, sometimes to the means by which it is transferred, sometimes to the whole process. In many cases, what is transferred in this way continues to be shared; if I convey information to another person, it does not leave my own possession through coming into his" (Ayer 1955: 12). 
questioned in terms of philosophy (and not, say, sociology or psychology), one should outline the philosophical context of these models ${ }^{4}$ to ensure consistency of argument. Perhaps the roots of this communication model run deeper than just the classical psychologism of Brentano and Mill. One of the most important of modern philosophical concepts that underpins today's psychologist-transmission communication theories is, I think, the Cartesian thesis of psychophysical dualism. It recognizes the subject as the composition of res extensa - the material, physical, sensory sphere responsible for physical contact with reality, and res cogitans - which is a kind of "psychological inner space", where mental acts take place (such as thinking, perception, understanding, etc.) and where the of content of experience is stored. The psychologist-transmission models accept exactly the same type (Cartesian) idea of the subject, which is described in them as a sender or recipient. However, they do not usually refer directly to the position of Descartes. Psycho-physical dualism as a binding interpretation of the subject was challenged in the philosophy long ago and in many respects, yet it persists, though petrified, in many communication theories.

Another source of psychologist-transmission models of communication can be found in genetic empiricism and representationism (especially in the form presented by John Locke and David Hume), and in the ensuing mentalist concept of meaning (as an inner, "spiritual" image or a process corresponding to the name). It is in the views of these British empiricists that we find the idea that words (names, signs) represent thoughts as thoughts represent things. Locke wrote,

A man may have a great variety of thoughts that could bring profit and delight to others as well to himself; but they are all locked up inside him, invisible and hidden from others, and incapable of being brought out into the open. If society is to flourish, thoughts must be communicated; so people had to devise some external perceptible signs through which they could let one another know of those invisible ideas of which their thoughts are made up (...). So this is what words are used for, to be perceptible marks of ideas; and the ideas they stand for are their proper and immediate signification (Locke 1975: 405).

Regardless of the changes brought about in the epistemology of Kant, his apriorism and transcendentalism also continue to foster the psychologist communication models. It is evidenced in the position of Humboldt (linguistic apriorism):

It [the language] is the ever-repeated mental labour of making the articulated sound capable of expressing thought (...). The mental activity which, as earlier explained, produces the expression of

4 It should be noted though that many - if not most - contemporary communication theorists ignore the achievements of modern philosophy in their research. They are, of course, not in any way required to resort to philosophy, although - as a philosopher - I think that the discourse on communication in the humanities would gain very much if it appealed to philosophy more boldly. Unfortunately, only two prominent "philosophers of communication" are recognized (Jürgen Habermas and Karl-Otto Apel), while one could find inspiration, or even solve many problems faced by the science of communication, in the works of such thinkers as Wittgenstein, Heidegger and Austin (not to mention the earlier philosophers such as Kant, Fichte and Humboldt). The fact that the abovementioned philosophers did not talk about communication expressis verbis does not indicate that their views are irrelevant to its research. Kant did not refer directly to the topics of culture or history; nevertheless he was invoked by the neo-Kantians interested in culture (Cassirer) or history (Rickert). 
thought, is always directed at once upon something given; it is not purely creative, but a reshaping activity (Humboldt 1988: 49).

Throughout almost the entire Western tradition of the mentalist paradigm it was assumed that the use of signs consists of correlations among (a) the external object, (b) its mental representation (idea, thought, presentation), and (c) its sensory representation (e.g. word, gesture, writing), which can be transferred to another subject, thereby transmitting the mental representation from one mind to another. Such an idea takes the form of the mentalist concept of meaning, criticized by Wittgenstein. According to Hans-Johann Glock,

According to the mentalist theory of meaning epitomized by Locke, the meaning of a word is an idea, an image in the mind of the speaker (...). For mentalism, communication is either a casual process by which speakers induce in their hearers ideas which are similar to the ones they associate with a word, or a matter of translation, with speakers translating their internal mental vocabulary into sounds which their hearers retranslate into their own private languages. This position implies that we can never know whether communication has been successful (Glock 1996: 372).

It was not until the early twentieth century that the mentalist paradigm was challenged and overcome in philosophy, mainly due to the linguistic turn and the achievements of, among others, Heidegger and the neopragmatists.

It is perhaps not surprising that psychologist-transmission communication models are no longer accepted uncritically, and that with the development of theoretical reflection on communication they are treated with increasing scepticism. What may be surprising is the fact that despite this criticism (and even regardless of it), models and ideas of this kind continue to be proposed and adopted, often without any reservations. The reason for this would be a subject for a different discussion. Nevertheless, I agree with Bruno Ollivier in his claim that

(...) communication can no longer be understood as sending the message which goes from the sender to reach the recipient. One has to understand that the circulation of messages by means of media which determine their content is subject to constant (re)interpretation by the users and active audience-readers. Stereotypes that assume purely telegraphic communication, derived from old work on the transfer of information, do not reflect the present state of science (Ollivier 2010: 368).

Emanuel Kulczycki comments on the transmission communication models with similar criticism:

The philosophical perspective on the origins of the transmissive way of perception of the communication process allows one to demonstrate that: (1) transmission is a category of insufficient (not so much wrong as inadequate) to explain communication practices, (2) the transmissive representation of communication is one of the reasons for the inability for an autonomous academic discipline reflecting on the process of communication to emerge, (3) in transmissive terms - from the perspective of contemporary philosophy - what should be criticized is not only the transmission category, but most of all the psychologising understanding of the sender and the recipient as a spontaneous origin (sender) and end (recipient) of the process: the sender and the recipient as the self-determined entities "detached" from culture (Kulczycki 2012: 16). 
Such opinions may be justified by philosophical arguments targeted at psychologism. However, since we are interested in the issue of communication, we ought to look for the form of anti-psychologism, which is most closely linked with the matter of language, understanding and communication. Therefore, the views of Frege and Husserl for example, which are polemic against psychologism within logic or epistemology, would be of less use in this case. The views of Ludwig Wittgenstein may be much more helpful, especially those present in his late philosophy.

\section{ANTI-PSYCHOLOGISM IN THE PHILOSOPHY OF LUDWIG WITTGENSTEIN}

The anti-psychologism (and anti-mentalism) of Wittgenstein's later work is particularly important for these considerations as it relates to the issues of language and such phenomena as understanding, thinking, intentionality, expressing feelings, and the formulation and testing of judgments. Thus Wittgenstein's version of anti-psychologism is a particularly useful tool for criticism of psychologism in communication theories. I assume that the concept of language games and its implications (such as criticism of a personal language, pragmatic concept of meaning and intentionality, or rejection of the post-Cartesian model of the subject) can be successfully used in the context of philosophical reflection on communication ${ }^{5}$. Wittgenstein is not widely regarded as a "philosopher of communication," and it is doubtful whether he himself would have agreed to such a term. Nevertheless, the intended non-regularity and a-theorising of his late philosophy - which "describes" rather than "explains" - allows for such an interpretation of Wittgenstein's description of linguistic phenomena, which would allow for the description to be successfully applied to the philosophical analysis of communication phenomena.

In his early views, e.g. in the Logical-Philosophical Treatise and other writings from the period of 1912-1922, Wittgenstein presents an anti-mentalist position close to that of Russell, and especially Frege, according to which thoughts are not "psychological acts", but sentences in the logical sense: "The logical picture of the fact is the thought. The thought is the significant proposition" (Wittgenstein 2009: 29-32). Rejection of the "picture" theory of language and his "pragmaticising" of linguistic issues, characteristic of his later works (after 1929 and especially since 1945), also involve a change - and a radicalisation - of the earlier version of anti-psychologism. The new version is found primarily in the Philosophical Investigations, but also in many other writings published after the philosopher's death (such as The Blue and Brown Books, Die Zettel, Remarks on the Philosophy of Psychology, et al.). The first to be

\footnotetext{
5 It is not possible - due to the limitations of this text - to justify this assumption in a comprehensive way. But I am convinced that the philosophy of "late" Wittgenstein has an enormous untapped potential that can be used in relation to the phenomena of communication, provided that they are to be a subject of philosophical reflection. A broader explanation of the possibility of application of at least some - yet crucial - elements of Wittgenstein's "late" philosophy in philosophical reflection on communication is the subject of current research interests of the author of this article.
} 
criticized is the mentalist concept of meaning, derived from the representationism of Locke and Hume: a word's meaning is not a mental state accompanying the word (pronouncing or hearing it), but "the meaning of a word is its use in the language" (Wittgenstein 1997: 20). It is an issue from the scope of semantics and pragmatics, less important in the study of communication, although it is worth noting that the "language game" itself as "the whole, consisting of language and the actions into which it is woven" (Wittgenstein 1997: 5) can be interpreted as a communication act ${ }^{6}$.

What is the essence of Wittgenstein's critique of psychologism in his late philosophy? It cannot be reduced to a single issue or a single solution which would have the form of a thesis. The author of Philosophical Investigation systematically avoids formulating any theses himself and his philosophical activity mainly consists of attacking various everyday ideas determined by the language we speak. Such everyday ideas cause a number of misunderstandings, mistakes and illusions, which - in his opinion - pervade philosophy and partly science. These include the idea of a mentalist character of meanings of words: "Wittgenstein also intimates doubt about the idea that when I speak, I must first think in some inner symbolism, linguistic or mental, and then transpose my thoughts into utterances of a different, public symbolism" (Glock 1996: 360). It is also related to the criticism of the notion of a private language and personal experience, and to the criticism of the privileged access of an individual to his "inner" world of thoughts and feelings, and above all to an attack on the idea of the existence of such an imminent private "mental realm":

One of our strongest beliefs is that psychological life takes place somewhere, that there is a certain place where the mental processes occur. That place is a broadly defined interior - something most private, best known and certifying our identity. According to Wittgenstein, the existence of the interior, understood as a place where our mental life happens, is an illusion (Gurczyńska 2007: 41).

The illusion is caused by how we imagine ourselves, which is predisposed by the language we use. One could say that the task realized by Wittgenstein is resisting the colloquial metaphor, struggling against the "violence of metaphors" which lead us philosophically astray ("A picture held us captive. And we could not get outside it, for it lay in our language and language seemed to repeat it inexorably", Wittgenstein 1997: 48). One such metaphor is the modern idea of communication as transmission of internal psychological content between Cartesian subjects.

In his posthumously published The Blue and Brown Books Wittgenstein refuted the assumption that a speech act (or an act of understanding) coexists with a mental act. He also repudiated the legitimacy of recognizing thinking as (only) a "psychological process". According to the Austrian philosopher, we have a tendency to accept that understanding of words, e.g. understanding of commands (i.e. messages) - which is the condition for its execution

6 The assertion that Wittgenstein's language games can be interpreted as communication acts can be substantiated by referring to the examples of language games he gives: “(...) giving orders, and obeying them, (...), reporting an event., speculating about an event, (...), making-up a story and reading it, play-acting, (...), asking, thinking, cursing, greeting, praying" (Wittgenstein 1997: 12). One can certainly recognize these - and similar - examples of language games as examples of communication acts. 
Anti-psychologism in Wittgenstein's philosophy in reference to theories of communication

- must be associated with a certain inherent psychological process, and the understanding itself is a phenomenon which takes place in the inner space of the mind:

It seems that there are certain definite mental processes bound up with the working of language, processes through which alone language can function. I mean the processes of understanding and meaning. The signs of our language seem dead without these mental processes; and it might seem that the only function of the signs is to induce such processes, and that these are the things we ought really to be interested in. Thus, if you are asked what is the relation between a name and the thing it names, you will be inclined to answer that the relation is a psychological one (...). We are tempted to think that the action of language consists of two parts; an inorganic part, the handling of signs, and an organic part, which we may call understanding these signs, meaning them, interpreting them, thinking (Wittgenstein 1998: 3).

The belief, this temptation, which Wittgenstein writes about, is definitely psychologist in nature, and as such becomes the object of his polemic. He argues that neither thought nor understanding need be interpreted by means of psychological terms as immanent phenomena, taking place in the "private" mental space. At the same time he proposes a remarkably pragmatic approach to thinking (or understanding) as an exclusively external form of action:

It is misleading than to talk of thinking as of a "mental activity". We may say that thinking is essentially the activity of operating with signs. This activity is performed by the hand, when we think by writing; by the mouth and larynx, when we think by speaking (...). If than you say that in such cases the mind thinks, I would only draw your attention to the fact that you are using a metaphor, that here the mind is an agent in a different sense from that in which the hand can be said to be the agent in waiting (Wittgenstein 1998: 6).

Thus, signs are handled within a language game and the process takes place only in the "public" (external, social, interpersonal) sphere, and the assumption about its possible correlation with psychological acts is unnecessary or even wrong. In his famous passage in Philosophical Investigations Wittgenstein illustrates this position with the excellent metaphor of the "beetle in a box":

Suppose everyone had a box with something in it: we call it a "beetle". No one can look into anyone else's box, and everyone says he knows what a beetle is only by looking at his beetle. - Here it would be quite possible for everyone to have something different in his box. One might even imagine such a thing constantly changing. - But suppose the word "beetle" had a use in these people's language? - If so it would not be used as the name of a thing. The thing in the box has no place in the language-game at all; not even as a something, for the box might even be empty (Wittgenstein 1997: 100).

The "box" can be understood as the Cartesian notion of mind as the "inner mental space," and the hypothetical beetle contained therein as a mentalist view on the meaning of the word "beetle". Wittgenstein notes that meaning thus presented remains non-intersubjective: "no one can look into anyone else's box". The meaning of the word "beetle" is the way it is used in a language game, whereas -very importantly - "the thing in the box has no place in the language-game at all". It implies that Wittgenstein does not deny the existence of internal 
mental processes which take place in the mind of an individual: there probably is indeed something in the box. The point is that such processes are permanently unavailable to other subjects and it is not them but only the external signs that are the elements of communication. Thus, it would appear that when studying communication phenomena one should take into account only that which takes place in the "public" sphere, whereas the alleged mental processes and the psychological content accompanying such phenomena should be disregarded. Wittgenstein concludes,

If I give someone an order I feel it to be quite enough to give him signs. And I should never say: this is only words, and I have got to get behind the words. Equally, when I have asked someone something and he gives me an answer (i.e. a sign) I am content - that was what I expected - and I don't raise the objection: but that is a mere answer. But if you say: "How am I to know what he means, when I see nothing but the signs he gives?" than I say: "How is he to know what he means, when he has nothing but the signs either?" (Wittgenstein 1997: 139).

Recalling the earlier example of the beetle, it could be claimed that in the psychologist-transmission approaches to communication, a notion of mind as a closed "box" is adopted, in which all one's mental contents, thoughts and feelings are kept. Communicating such psychological content would consist of their expression, externalisation with a word or another sign. Whereas Wittgenstein simplifies and "pragmaticises" such a description of a process. Communication - as an example of social practice and also an object of study - would not be transmitting, transmission, nor transfer of psychological content between the subjects, but it would be an act of sign manipulation, and therefore a symbolic interaction. Its understanding (or interpreting, being the recipient's responsibility) would not consist of "repackaging the beetle from one box to another", but of responding, which we are taught in accordance with the rules of the language game we have been imbued with, in accordance with the "form of life" we have adopted - and these rules and the "form of life" are the socio-cultural rules and norms. Thus, the study of communication would consist of observing, identifying and describing the symbolic interactions determined by social principles, while the immanent "private, inner mental space" of the subject would be of no consequence here simply by virtue of being inaccessible.

\section{CONCLUSION}

It seems the anti-psychologist blade of Wittgenstein's argument is aimed primarily at the post-Cartesian idea of the subject and at the representationist, mentalist interpretations of language: "One unifying theme in this area is his [Wittgenstein's] enduring hostility to the idea of an individuated, substantive self. Insofar as the belief in such a self is most easily associated with Descartes, we can call Wittgenstein's position as anti-Cartesianism" (Sluga 1996: 321). It is not a regular behaviorism, though, or a naive denial of the existence of psychic phenomena. When we participate in a communication process or when we observe such a process, we tend to imagine that in parallel with the spoken words, in the minds of the participants of the process, the associated mental processes, constituting the communicative action, take place. According to Wittgenstein, it might, but does not have to be the case psychological acts therefore do not constitute the communicative act: 
Anti-psychologism in Wittgenstein's philosophy in reference to theories of communication

Supposing I teach someone the use of the word "yellow" by repeatedly pointing to a yellow patch and pronouncing the word. On another occasion I make him apply what he has learnt by giving him the order, "choose a yellow ball out of this bag". What was it that happened when he obeyed my order? I say "possibly just this: he heard my words and took a yellow ball from the bag". Now you may be inclined to think that this couldn't possibly have been all; and the kind of thing that you would suggest is that he imagined something yellow when he understood the order, and then chose a ball according to his image. To see that this is not necessary remember that I could have given him the order, "Imagine a yellow patch." Would you still be inclined to assume that he first imagines a yellow patch, just understanding my order, and then imagines a yellow patch to match the first? (Wittgenstein 1998: 11).

It appears that Wittgenstein is suggesting that the description of an act which involves issuing a command and executing it (the description of a language game, understood as a communication situation) should be reduced to a description of uttering of words (using signs) and responding to them, where the action is the result of the "rules of the game" adopted by the sender and the recipient. Whereas, such a description does not need to (or indeed may not) contain a description of the alleged psychological acts accompanying the actions.

Let us consider the situation of a game of chess, contemplated by Wittgenstein in the Investigations... Would we not conclude that in the minds of the players certain intellectual operations and mental processes which result in the moves of pieces (which are the consequences, external manifestations and implementations of the player's thoughts), take place? But the external, socially determined rules of the game that determine the actions of players are at least as important here. The movement of a piece is not only a realization of a thought, but also a realization of a certain external convention. While that which is available to the player (relative to his partner), as well as to a third party observing the game, are only the external operations, actions interpreted by means of the intersubjective rules and carried out according to them. It appears that the criteria of the intersubjective communicability of operations performed by the players on the board are located not in their "private", internal psychological processes, but in an external, socio-cultural, "public" area of interaction. Katarzyna Gurczyńska writes, "We think, feel and experience emotions as dictated by social rules that we assimilate. The source of what we call our inner life is outside" (Gurczyńska 2007: 259).

It is worth noting that the situation of the game of chess (or other games cited by Wittgenstein) may serve as an excellent example of a communication act, where players act as a sender and recipient, and the figures are a means of communication. This observation supports a postulate for a departure from the psychologist (transmission) "explanation" of communication acts and its replacement with the pragmatic "description".

\section{BIBLIOGRAPHY}

Ayer, Alfred. 1955. What is Communication?, in: Studies in Communication. Communicaton Research Centre, London: Sacker and Warburg, pp. 11-28.

Berelson, Bernard and Gary Steiner. 1964. Human Behavior, New York: Harcourt, Brace and World. 
Galvin, Kathleen and Charles Wilkinson. 2006. The Communication Process. Impersonal and Interpersonal, in: Kathleen Galvin (ed.), Making Connections: Readings in Relational Communication, Oxford: Univesity Press, pp. 4-10.

Glock, Hans-Johann. 1996. A Wittgenstein Dictionary, Oxford: Blackwell.

Gurczyńska, Katarzyna. 2007. Podmiot, jako byt otwarty. Problematyka podmiotowości w późnych pismach Wittgensteina, Lublin: Wydawnictwo UMCS.

Hoben, John. 1954. English Communication at Colgate Re-Examined, "Journal of Communication" 4: 76-86.

Hovland, Carl. 2007. Social Communication, in: Robert T. Craig, Heidi L. Muller (ed.), Theorizing Communication. Reading across Traditions, Los Angeles: Sage.

Humboldt, Wilhelm von. 1988. On Language: The diversity of human language-structure and its influence on the mental development of mankind, Cambridge: University Press.

Husserl, Edmund. 2001. The Shorter Logical Investigations, London \& New York: Routledge. Kulczycki, Emanuel. 2012. Źródła transmisyjnego ujęcia procesu komunikacji, "Studia Humanistyczne AGH” 1: 21-36.

Locke, John. 1975. An Essay Concerning Human Understanding, Oxford: Clarendon.

Mohanty, Jitendranath. 1982. Husserl and Frege, Bloomington: Indiana University Press.

Newcomb, Theodore. 1966. An Approach to the Study of Communication Acts, in: Alfred G. Smith (ed.), Communication and Culture, New York: Holt, Rinehart and Winston, pp. 66-79.

Sluga, Hans. 1996. "Whose House is That?”. Wittgenstein on the Self, in: Hans Sluga and David G. Stern (ed.), The Cambridge Companion to Wittgenstein, Cambridge: University Press, pp. 320-353.

Windelband, Wilhelm. 1993. Lehrbuch der Geschichte der Philosophie, Tübingen: Mohr Siebeck.

Wittgenstein, Ludwig. 1997. Philosophical Investigations, Oxford: Blackwell.

Wittgenstein, Ludwig. 1998. The Blue and Brown Books, Oxford: Blackwell.

Wittgenstein, Ludwig. 2009. Tractatus Logico-Philosophicus, New York: Cosimo.

\section{ANTYPSYCHOLOGIZM W FILOZOFII WITTGENSTEINA A TEORIE KOMUNIKACJI}

Celem artykułu jest prześledzenie zasadności krytycyzmu wobec tzw. psychologistyczno-transmisyjnych teorii komunikacji. Za teorie takie uznaje się te, w których zawarty jest pogląd, iż komunikacja to proces przekazywania (transmisji) treści psychicznych (stanów mentalnych) między biorącymi w nim udział podmiotami (np. teorie Jakobsona, Hovlanda, Newcomba i in.). Wątpliwości wobec takich stanowisk wynikają z założeń antypsychologizmu i antymentalizmu (np. Frege, Husserl), a także z odrzucenia tradycyjnych wyobrażeń o podmiotowości w filozofii po zwrocie lingwistycznym. W celu uzasadnienia krytyki przywoływane jest stanowisko tzw. „późnego” Wittgensteina, zgodnie z którym działania komunikacyjne (a także procesy myślenia, rozumienia itp.) nie muszą być ujmowane jako skorelowane z aktami mentalnymi.

Słowa kluczowe: Wittgenstein, działanie komunikacyjne, teoria komunikacji, psychologizm, antypsychologizm 